\title{
Scanning Electron Microscopy study of root tissue of muskmelon: Transferring Fusarium wilt resistance from snapmelon to muskmelon
}

\author{
Anu Kalia ${ }^{1 *}$, Sat Pal Sharma ${ }^{2}$ and Vinod Kumar Vashisht ${ }^{2}$ \\ ${ }^{1}$ Electron Microscopy and Nanoscience Laboratory, Department of Soil Science, Punjab Agricultural University, \\ Ludhiana-141004 (Punjab), INDIA \\ ${ }^{2}$ Department of Vegetable Science, College of Agriculture, Punjab Agricultural University, Ludhiana-141004 \\ (Punjab), INDIA \\ *Corresponding author.E-mail: kaliaanu@pau.edu
}

Received: October 5, 2016; Revised received: February 23, 2017; Accepted: June 28, 2017

\begin{abstract}
The overall aim of this study was to investigate the level of Fusarium oxysporum f. sp. Melonis (F.o.m.) infection by studying the Scanning electron micrographs of transverse sections of parent inbred lines and developed F1 hybrid. The current study involved $\mathrm{KP}_{4} \mathrm{HM}-15$ (Fusarium wilt resistant inbred line) in a crossing program with well adapted muskmelon cv. Punjab Sunehri (PS) to develop FW resistant hybrid possessing high yield and quality traits. Fom infects melon root and trails through the cortical and endodermal cells to reach xylem vessels by penetrating through pits. This is the first SEM appraisal of the whole tap root of field grown melon accessions, $\mathrm{KP}_{4} \mathrm{HM}-15$, PS and $\mathrm{PSxKP}_{4} \mathrm{HM}-15(\mathrm{MH}-41)$ ( $\mathrm{F} 1$ hybrid) aimed to discern the role of the root morphometric characters for imparting $\mathrm{FW}$ resistance. The trend for root epidermo-cortical thickness was $\mathrm{KP}_{4} \mathrm{HM}-15>\mathrm{PS}>\mathrm{MH}-41$ while for the xylem diameter was $\mathrm{MH}-41>\mathrm{KP}_{4} \mathrm{HM}-15>\mathrm{PS}$. The $\mathrm{F} 1$ hybrid exhibited $\mathrm{FW}$ resistance intermediate among the two parents i.e. absence or presence of less mycelia as compared to the susceptible parent (PS). However, the extent of infection was higher than the resistant parent $\mathrm{KP}_{4} \mathrm{HM}-15$, which shows that partial resistance was transferred from $\mathrm{KP}_{4} \mathrm{HM}-15$ to $\mathrm{MH}-41$. This study accentuates the resistance gene mining and use of wild melon accessions to introgress FW resistance in commercial melon cultivars.
\end{abstract}

Keywords: Electron microscopy, Fusarium, Resistance genes, Snap melon, Xylem vessel

\section{INTRODUCTION}

Melon (Cucumis melo L.) is an economically important vegetable crop grown for its low calories, fat and cholesterol free, nutritious, sweet and juicy fruits. Melon fruits are good source of minerals and antioxidant compounds such asascorbic acid and beta $\beta$-carotene (Saftner and Lester, 2009; Rajsree et al., 2016). It is a diverse species which has been further divided into sixteen morphotypes (Pitrat, 2008). Melons exhibit a considerable intraspecific diversity for morphological, anatomical, biochemical and physiological characteristics. The morphological variability is primarily exemplified as differences in the fruit characteristics such as shape, size, color, fruit cavity diameter, rind thickness, presence of netting or ribs and taste (Rashidi and Seyfi, 2007; Yousif et al., 2011). Further, Davis et al. (1967) have mentioned variations in the leaf morphology including the leaf lamina thickness, presence and thickness of waxy cuticle, abaxial and adaxial stomatal density, trichome length and density, and angle of petiole attachment. Similarly, the intraspecific diversity has been reported in root traits such as specific root length, volume and, biomass. The root anatomical features such as, thickness of root epidermis, diameter of proto- and meta-xylem vessels and the compactness of the pith also vary among the melon cultivars (SalehiMohammadi et al., 2009). This variation in root histological traits is useful not only as first line of physical defense to ward off certain soil-borne fungal pathogens but also for water and mineral uptake due to variations in xylem anatomy and hydraulic properties (McElrone et al., 2004).Therefore, morphological and anatomical properties of root system affect fruit yield and quality traits (Lester, 1997). Root traits alter the extent of fungal infection process that may vary with cultivars exhibiting susceptibility or resistance to a particular fungal disease. This may result in development of asymptomatological infections or lengthened restriction of the trailing fungal hyphae at certain region(s) of the root.

Melons are susceptible to numerous foliar and soil-borne pathogenic microbes. A soil-borne pathogen, Fusarium oxysporum Schlechtend: Fr. f. sp. melonis (H.N. Hansen) W.C. Snyder \& H.N. Hans (F.o.m) causes muskmelon Fusarium wilt (MFW). The MFW decreases both fruit yield and quality apart forcing intensive use of chemical fungicide sprays (Gordon et al. 1990, Oumouloud et al., 2013). The 
formation of perennating chlamydo spores in soil by this fungus and the ability to infect and colonize the root system of non-host plants and melon rotation crops equips it to sustain its population in soil over gap and crop cover other than melon (Gordon et al., 1989). $F$. oxysporum infection in melon occurs through step-wise chronologically ordered complex host-pathogen interaction cascades involving host root recognition, fungal adsorption followed by hyphal penetration through different root tissues, finally penetration and progression in the xylem and hyphal adaptation to the internal plant environment. The infection process of fom involves progression through the root epidermis, outer and inner cortical tissues, endodermis and finally penetration of the xylem vessels through the pits. After infecting xylem, vertical movement of infection occurs by germination of sporulated micro conidia at the vessel endplates so that the secondary hyphae penetrate next vessel. Finally, disease symptoms appear (necrotic lesions, chlorosis, wilting) due to secretion of lytic enzymes (Zvirin et al., 2010).

The resistant and susceptible genotypes of melon vary considerably in the extent of infection or days taken for the progression of the disease (Zvirin et al., 2010, Herman et al., 2010). As a part of the infection process, a successful infection is established if the fungus overcomes different plant defense responses at each stage (Michielse and Rep, 2009). There occurs variation in biochemical and enzymatic profile of resistant and susceptible melon cultivars. The synthesis and amount of secondary metabolites i.e. phytoalexins, enzymes defending reactive oxygen species (ROS), and cell wall-building processes like necrosis, callose deposition and lignification in response to invasion by fungal pathogens play a vital role in imparting resistance to F.o.m infection (Oumouloud et al., 2013).

The F.o.m. isolates have been categorized into four physiological races i.e. $0,1,2$ and 1.2, based on the host resistance genes (Perchepied and Pitrat, 2004). Many wild melon accessions are known to bear resistance genes to control F.o.m. infection. Therefore, FWD can be effectively controlled through the use of disease-resistant cultivars. However, there exist certain constraints for the development of a successful hybrid that combine both the useful horticultural traits as well as the resistance profile to the local F.o.m races. Pathogen nature/ diversity and virulence, type of resistant gene, and the tool/ technique for assessing the host resistance to resident/ indigenous F.o.m races are the factors that influence the development of a successful hybrid. The resistance genes may exist as dominant or recessive alleles. Thus, a resistant host may bear dominant genes, Fom-1 and Fom-2, to control 0 and 2, and 0 and 1, respectively. However, a partial resistance to race 1.2 is imparted by polygenic recessive genes (Risser et al., 1976). The F.o.m. race 1.2 is further categorized as yellow inducing (pathotype 1.2Y) and wilt causing pathotypes (pathotype 1.2W). Mahdikhani (2016) has reported the existence of polyphyletic nature of the melon pathotypes of Fusarium. He reported occurrence of clades sharing isolates infecting watermelon, tomato and muskmelon on phylogenetic analysis of the Translation Elongation Factor $1 \alpha$ (TEF $1 \alpha$ ) sequences. Therefore, resistance against FWD in muskmelon cultivars is governed by an array of morphological, biochemical and enzymatic characteristics of the melon root. Oumouloud et al. (2013) have reported that the root morphological traits and the ROS neutralizing enzymes are involved in imparting resistance in melon genotypes against FWD. Thus, this study was conducted to elucidate the root anatomical differences among the susceptible and resistant muskmelon hybrids for F.o.m infection and the effect of FWD on the fruit yield and quality. The findings of this study would be useful for screening melon germplasm against FWD.

\section{MATERIALS AND METHODS}

Melon accessions: Three melon accessions, $\mathrm{KP}_{4} \mathrm{HM}-$ 15, Punjab Sunehri (PS) and F1 hybrid (MH-41) were used in the current study. F1 hybrid (MH-41) was generated from a cross between $\mathrm{KP}_{4} \mathrm{HM}-15$, as female parent and PS as male parent. The female parent of the hybrid was derived from a backcross breeding program involving a MFW resistant inbred line of snapmelon (Cucumis melo var momordica) accession $\mathrm{KP}_{4}$ and $\mathrm{HM}$, a well adapted and sweetest melon cultivar by following a series of inbreeding and selection in $\mathrm{KP}_{4} \mathrm{HM}$ progenies for five successive years to recover superior fruit quality traits along with high fruit yield potential and resistance to Fusarium wilt resulting in the development of an inbred line, $\mathrm{KP}_{4} \mathrm{HM}$ -15. The male parent, Punjab Sunehri a moderately MFW susceptible was used due to the presence of superior fruit quality characters.

The melon seedlings were raised by sowing melon seeds in polybags (one or two per polybag) in the second week of February 2015. Thirty days old seedlings (at the two-three true leave stage) were transplanted in field in mid March 2015 in four rows in triplicate. Recommended package of practices for muskmelon were followed for raising the crop.

Yield and yield attributing characteristics: The fruits were harvested from five random plants. They were graded for five qualitative traits i.e. fruit and flesh color, fruit cavity area, presence or absence of fruit netting and sutures. Three quantitative traits (fruit weight, total soluble solid content, and fruit shape) of the parents and hybrid were also measured. The fruits were harvested from each vine and average of these fruits was estimated as fruit weight. The number of fruits per vine was calculated by counting total number of fruits harvested from each vine. The fruit shape 
index was also determined as the ratio of fruit length to fruit diameter. Fruit shape was observed to be round, elongated or oval and flat for ratio 1 , less than 1 or greater than 1.3 and between 1 to 1.3 , respectively. The fruit cavity was measured by using the polar diameter of seed cavity as length and equatorial diameter of seed cavity as a breadth and calculated area of fruit cavity $(\mathrm{cm})$.

Incidence of Fusarium wilt: The relative difference in the extent of resistance against Fusarium wilt under epiphytotic conditions was evaluated. The number of vines affected by the disease was counted. Data was also recorded in number of days taken for plant death.

Scanning electron microscopy (SEM): The melon roots were sampled from field in the end of May 2015. These roots were thoroughly washed with tap water followed by distilled water (three to four times) to remove the adhering soil/ organic matter particles. The SEM of the melon roots was performed by cutting the tap root at the root-shoot junction and large lateral root arising from primary root into approximately $1 \mathrm{~cm}$ long transverse sections. These sections were chemically fixed in $2.5 \%$ Glutaraldehyde solution (primary fixative) for 24 hours at $4^{\circ} \mathrm{C}$ and osmium tetraoxide (secondary fixative) followed by dehydration using graded ethanol series (from 30 to 100\%). The dehydrated tissue was later critical point dried in Leica EM CPD (model 300 Auto) and gold sputter coated in Hitachi E-1010 Ion sputter coater. The sputtered samples were viewed in Hitachi S-3400N SEM at $15.0 \mathrm{kV}$ accelerating voltage in Secondary electron imaging mode (Bozzola and Russell, 1999).

Two each main and lateral root sections were thoroughly viewed for the presence of F.o.m mycelia network in cortex/ vascular tissue, microconidia, germinating microconidia and secondary hyphal infection in the xylem vessel members. The root sections were graded as highly infected, if the Fusarium hyphal network was visible in more than five to six xylem vessels in one frame at lower magnification (100x to 160x). Moderately infected root sections exhibited the presence of hyphae across the diameter of the xylem vessel member in one to three vessel members. Resistance to F.o.m was recorded for absence of any hyphal network in the xylem vessels and cortical tissues.

\section{RESULTS AND DISCUSSION}

Yield and yield contributing characteristics: The yield was recorded for fruits for both qualitative as well as quantitative traits. The fruit shape index was measured. The fruits of $\mathrm{KP}_{4} \mathrm{HM}-15$ and Punjab Sunehri were oval round while that of $\mathrm{MH}-41$ were oblong. The female parent $\left(\mathrm{KP}_{4} \mathrm{HM}-15\right)$ fruits were non-netted, light green sutured, greenish yellow in colour having 11.0 to $13 \%$ TSS. The average yield of the fruits was also high (16.8 $\left.\mathrm{t} \mathrm{ha}^{-1}\right)$ (Table 1). The male parent

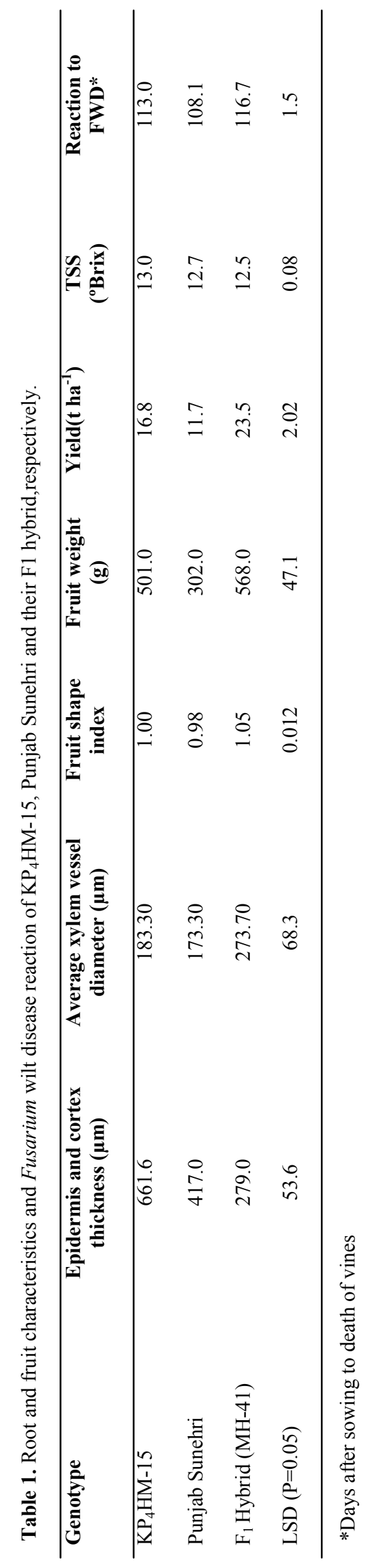




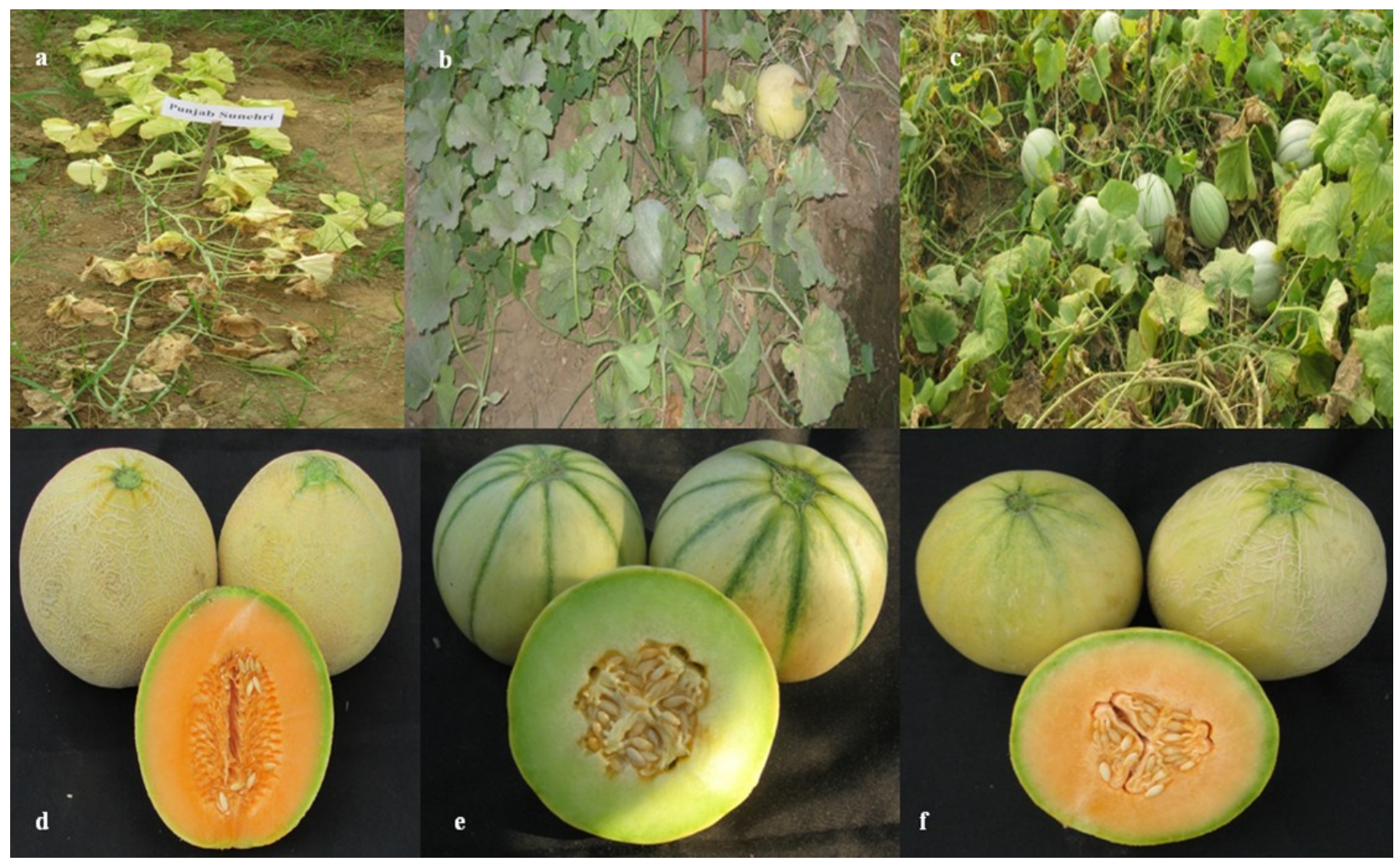

Fig. 1. Field incidence of Fusarium wilt disease and fruit characteristics of parents and $F_{1}$ hybrid. a) PS (Male Parent), b) $\mathrm{KP}_{4} \mathrm{HM}-15$ (Female Parent), c) F1 hybrid (MH-41), d) Fruit of PS, e) Fruit and fruit cavity of $\mathrm{KP}_{4} \mathrm{HM}-15$ and f) Fruit and fruit cavity of $M H-41$.

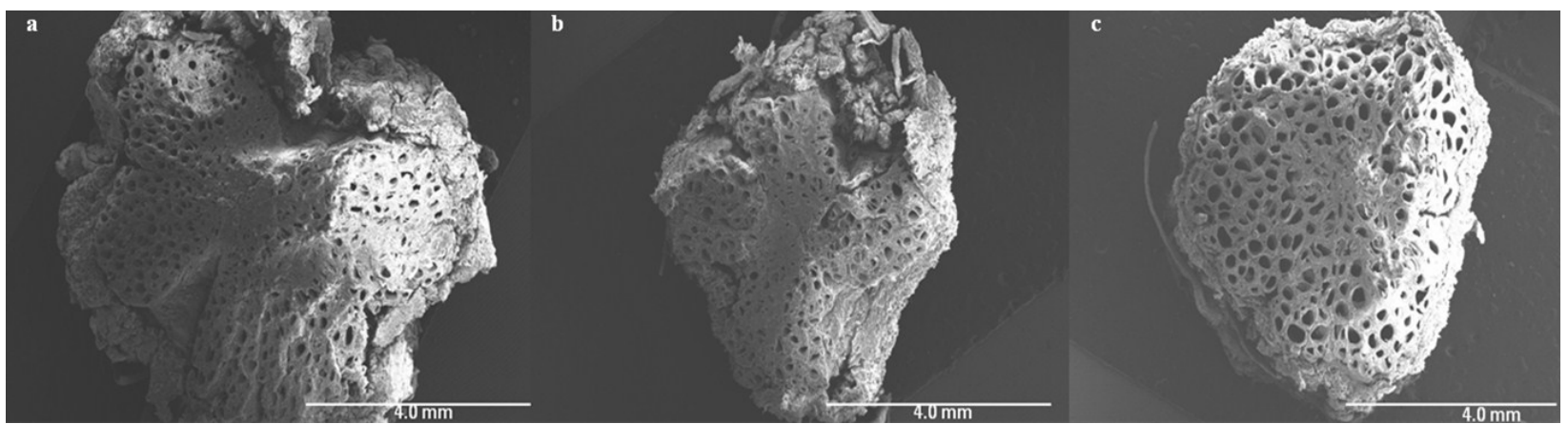

Fig. 2. Scanning Electron micrograph showing variation among the pith compactness and occurrence of wider xylem vessels in the parents and $F_{1}$ hybrid. a) $\mathrm{KP}_{4} \mathrm{HM}-15$ (Female Parent), b) PS (Male Parent), c) F1 hybrid (MH-41).

(Punjab Sunehri) recorded a high yield $\left(11.7 \mathrm{t} \mathrm{ha}^{-1}\right)$ of netted, non-sutured fruits having an equivalent TSS content $(12.7 \%)$ (Table 1$)$. The $\mathrm{F}_{1}$ hybrid had a total yield of $23.5 \mathrm{t} \mathrm{ha}^{-1}$ which is $10 \%$ higher than the commercial hybrid, Punjab Hybrid (21.4 t ha ${ }^{-1}$ ). Fruits were light yellow, netted, non-sutured with thick rind weighed about $850 \mathrm{~g}$. Fruit flesh is thick, salmon orange and green near the rind with medium juiciness and high TSS (12.5\%) (Fig. 1). Thus, the F1 hybrid showed heterosis for total yield mainly attributed to increase in size as well as number of fruits. Similarly, significant heterosis values for melon fruit yield have been reported by Nerson (2012). However, the superiority of the melon hybrid in fruit yield was mainly due to larger fruits rather than due to increased fruit num- ber.

Fusarium wilt incidence: The general symptoms on Fusarium infection include wilting, necrosis, gum exudates, stunting and discoloration as observed in melon male parent under field conditions (Punja et al., 2001). Mahdikhani (2016) also reported that Fusarium wilt affected melons exhibit prominent symptoms of wilting, yellowing and chlorosis of the foliage, less or no fruit bearing in partially affected vines, and finally decay of roots and death under severe infection conditions. The resistance to Fusarium wilt disease in the male and female parents of the hybrid is low and high, respectively. The disease severity (30\%) and disease intensity $(25 \%)$ was recorded for $\mathrm{KP}_{4} \mathrm{HM}-15$ while Punjab Sunehri was severely affected by the 


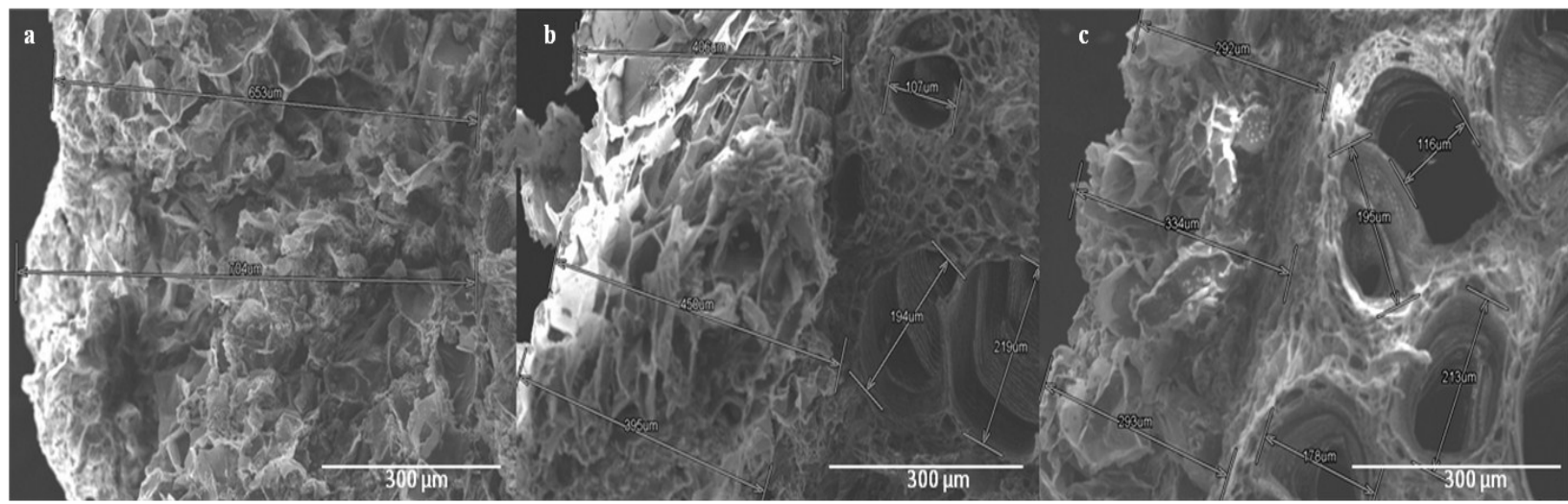

Fig. 3. Scanning Electron micrograph depicting variation in the epidermis and cortical tissue thickness in parents and $F_{1}$ hybrid a) $\mathrm{KP}_{4} \mathrm{HM}-15$ (Female Parent), b) PS (Male Parent), c) F1 hybrid (MH-41).

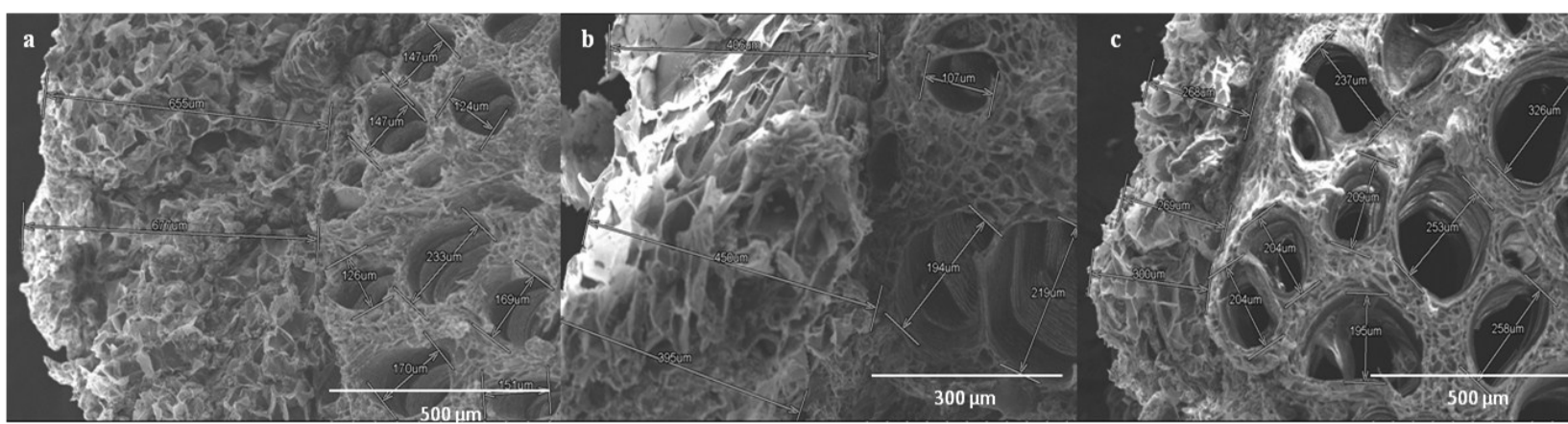

Fig. 4. Scanning Electron micrograph showing variation in the xylem vessel diameter in parents and $F_{1}$ hybrid) a) $K P_{4} H M-15$ (Female Parent), b) PS (Male Parent), c) F1 hybrid (MH-41).

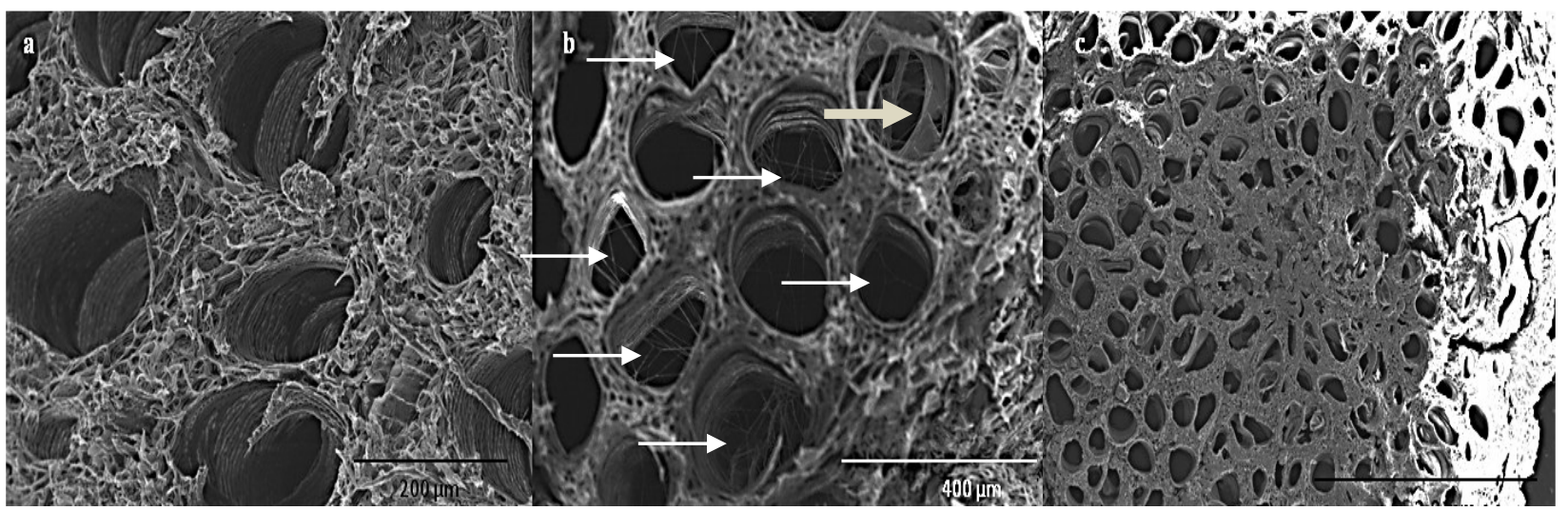

Fig. 5. Scanning Electron micrographdepicting the difference in the extent of fungal infection and xylem occlusion in parents and $F_{1}$ hybrid. a) $\mathrm{KP}_{4} \mathrm{HM}-15$ (Female Parent), b) PS (Male Parent), c) F1 hybrid (MH-41). *White arrows indicating the occlusion of the xylem vessel diameter by Fusarium hyphal network and grey arrow indicating deposition due of secretory products of Fusarium in infected vessel.

disease (100\%) (Plate 1). The disease severity symptoms matched as described by Mahdikhani (2016). The MH-41 $F_{1}$ hybrid exhibited disease reaction similar to the female parent, $\mathrm{KP}_{4} \mathrm{HM}-15$.

Scanning electron microscopy (SEM) of melon roots for fungal infection: The melon roots are the target site for the infection by Fusarium and the morphological and biochemical characteristics of the roots are expected to alter the extent of infection and disease severity. The SEM of the main and lateral root transverse sections showed marked differences in the root tissue anatomy in the three melon genotypes. Figure 2 shows presence of compact pith in both parent melon lines though the pith compactness was observed to be intermediate for the $F_{1}$ hybrid. There is also variation in the epidermis and cortical tissue thickness among the tested cultivars which suggest that thickness criterion is not responsible for imparting resistance in $F_{1}$ hybrid (Fig. 3). The variation in the disease severity among these three genotypes may be 
attributed to the production of specific alleochemicals that get translocated to the aerial parts through xylem to impart resistance to Fom (Rajsree et al., 2016; Biles et al., 1989). However, both the parent melon genotypes exhibited statistically significant higher epidermis and cortex tissue thickness than that the hybrid (Table 1). A reverse trend for the xylem diameter was observed for the hybrid as it was statistically higher over both the parents (Table 1). This approximately 1.5 times higher xylem vessel diameter recorded in root sections of $F_{1}$ hybrid (Fig. 4) may be responsible for higher acquisition of nutrients and water by the root system. Similar observation of benefit of a vigorous root system for enhanced water and mineral uptake by the grafted rootstock has been reported (Lee, 1994). The hyphal penetration through the root tissues and infection in the xylem vessels was observed to be very high for PS (Fig. 5). As reported by Lorenzini et al. (1997) increased resistance to water flow occurs within the plant due to xylem colonization and occlusion by $F$. oxysporum. Further, it may result in leaf water deficits leading to reduced leaf photosynthetic and transpiration rates. No infection could be observed in the xylem vessels of the female parent and the $\mathrm{F}_{1}$ hybrid.

\section{Conclusion}

Resistance for Fusarium wilt disease in muskmelon cultivars can be introgressed by cross breeding the cultivars having best fruit quality traits with the wild melon relatives. This is the first Scanning Electron Microscopy appraisal of the transverse sections of the main tap root of the parent inbred lines and their F1 hybrid .The investigation clearly indicates the positive impact of xylem vessel diameter (1.5 times higher than the parents in order $\left.\mathrm{MH}-41>\mathrm{KP}_{4} \mathrm{HM}-15>\mathrm{PS}\right)$. The tissues sections of F1 hybrid exhibited no or less presence of mycelia as compared to the susceptible parent Punjab Sunehri. Besides showing FWD resistance, the F1 hybrid also exhibited yield hetrosis (23.5 $\left.\mathrm{t} \mathrm{ha}^{-1}\right)$ and TSS content $\left(12.5^{\circ} \mathrm{Brix}\right)$ at par to that of the parent lines. Further, research interventions are required to ascertain the involvement of type and amount of the diffusible signal compounds responsible for imparting resistance to FWD in the resistant parent and F1 hybrid.

\section{ACKNOWLEDGEMENTS}

The authors are thankful to the Head, Department of Soil Science and Dean, College of Agriculture, Punjab Agricultural University, Ludhiana for providing the necessary financial and infrastructural support.

\section{REFERENCES}

Biles, C.L., Martyn, R.D. and Wilson, H.D. (1989). Isozymes and general proteins from various watermelon cultivars and tissue type. HortScience, 24:810-812
Bozzola, J.J. and Russell, L.D. (1999). Electron Microscopy. Second edition, Johns and Bartlett Publishers Inc., MA, USA.

Davis, R.M., Davis, G.N. and Meinert, U.G.H. (1967). Genetic and environmental correlations of leaf and fruit shapes of Cucumis melo. Eco. Bot., 21(4):345-350

Gordon, T.R., Jacobson, D.J., May, D.M., Tyler, K.B. and Zink, F.W. (1990). Fruit yield, disease incidence, and root colonization of hybrid muskmelons resistant to Fusarium wilt. Plant Dis., 74:778-781

Gordon, T.R., Okamoto, D. and Jacobson, D.J. (1989). Colonization of muskmelon and non-host crops by Fusarium oxysporum f. sp. melonis and other species of Fusarium. Phytopathol., 79:1095-1100

Herman, Z.T., Brotman, R.Y., Denisov, Y., Belausov, E., Freeman, S. and Perl-Treves, R. (2010). Differential colonization and defence responses of resistant and susceptible melon lines infected by Fusarium oxysporum race 1.2. Plant Pathol. 59:576-585. doi: 10.1111/j.1365-3059.2009.02225.x.

Lee, J.M. (1994). Cultivation of grafted vegetables: I. Current status, grafting methods, and benefits. HortScience, 29:235-239

Lester, G. (1997). Melon (Cucumis melo L.) fruit nutritional quality and health functionality. HortTechnol., 7(3):222 $-227$

Lorenzini, G., Guidi, L., Nali, C., Ciompi, S. and Soldatini, G.F. (1997). Photosynthetic response of tomato plants to vascular wilt diseases. Plant Sci.,124:143-152

Mahdikhani, M. (2016). Genetic variability among Fusarium oxysporum isolates from melon (Cucumis melo) in Qazvin province, Iran. Horticultural Biotechnol. Res., 2:1-7. doi: 10.19071/jhcbt.2016.v2.2996

McElrone, A.J., Pockman, W.T., Martínez-Vilalta, J. and Jackson, R.B. (2004). Variation in xylem structure and function in stems and roots of trees to $20 \mathrm{~m}$ depth. New Phytol., 163:507-517

Michielse, C.B. and Rep, M. (2009). Pathogen profile update: Fusarium oxysporum. Mol. Plant Pathol., 10:311-324

Nerson, H. (2012) Heterosis in fruit and seed characters of muskmelon. The Asian Aus. J. Plant Scis. Biotechnol., 6 (1):24-27

Oumouloud, A., El-Otamani, M., Chikh-Rouhou, H., Claver, A.G., Torres, R.G., Perl-Treves, R. and Alvarez, J.M.A. (2013). Breeding melon for resistance to Fusarium wilt: Recent developments. Euphytica, 192:155-169. doi 10.1007/s10681-013-0904-4.

Perchepied, L.and Pitrat, M. (2004). Polygenic inheritance of partial resistance to Fusarium oxysporum f.sp. melonis race 1.2 in melon. Phytopathol., 94:1331-1336

Pitrat, M. (2008). Melon (Cucumis melo L.). Handbook of Plant Breeding, Vol I- Vegetables, Springer, New York, USA, Pp. 283-315

Punja, Z.K., Parker, M. and Elmhirst, J.F. (2001). Fusarium wilt of field-grown muskmelon in British Columbia. Can. J. Plant Pathol., 23:403-410

Rajsree, R.S., Sibi, P.I., Femi, F., William, H. (2016). Phytochemicals of Cucurbitaceae Family-A Review. Intl. J. Pharmacognosy Phytochem. Res., 8(1):113-123

Rashidi, M. and Seyfi, K. (2007). Classification of fruit shape in cantaloupe using the analysis of geometrical attributes. World J. Agricultural Scis., 396:735-740

Risser, G., Banihashemi, Z. and Davis, D. (1976). A proposed nomenclature of Fusarium oxysporum f. sp. melonis 
Anu Kalia et al., / J. Appl. \& Nat. Sci. 9 (3): 1317 - 1323 (2017)

races and resistance genes in Cucumis melo [Muskmelon, fungal diseases]. Phytopathol., 66:11051106

Saftner, R.A. and Lester, G.E. (2009). Sensory and analytical characteristics of a novel hybrid muskmelon fruit intended for the fresh-cut industry. Postharvest Biol.Technol., $51: 327-333$

Salehi-Mohammadi, R., Kashi, A., Lee, S.G., Hu, Y.C., Lee, J.M., Babalar, M. and Delshad, M. (2009). Assessing the survival and growth performance of Iranian melon to grafting onto Cucurbita rootstocks. Korean J. Horticultural Sci. Technol., 27(1):1-6
Yousif, M.T., Elamin, T.M., Baraka, A.F.M., El-Jack, A.A. and Ahmed, E.A. (2010-2011).Variability and correlation among morphological, vegetative, fruit and yield parameters of snake melon (Cucumis melo var. flexuosus). Cucurbit Genetics Cooperative Rep., 3334:32-35

Zvirin, T., Herman, R., Brotman, Y., Denisov, Y., Belausov, E., Freeman, S. and Perl-Treves, R. (2010). Differential colonization and defence responses of resistant and susceptible melon lines infected by Fusarium oxysporum race 1.2. Plant Pathol., 59:576-585. doi: 10.1111/j.1365-3059.2009.02225.x 